\title{
A Case Report on Cyanotic Spell: Suspected Foreign Body
}

\begin{abstract}
Tracheobronchial Foreign Body Aspiration (FBA) remains a significant cause of morbidity and mortality in children less than three years of age. High index of suspicion leads to early diagnosis and treatment thus preventing further deleterious complications. This case report is about a 15-month-old female child who presented with intermittent low-grade fever, cough, cold for 20 days and rapid breathing since one day. On examination, she had pallor, grade 3 protein energy malnutrition according to Indian Academy of Paediatrics classification, heart rate was $128 / \mathrm{min}$, respiratory rate was $44 / \mathrm{min}$, oxygen saturation was $88 \%$ on room air with nasal flaring, intercostal and subcostal retractions. Bilateral rhonchi with reduced air entry was present in all areas of the lung. Bilateral bronchopneumonia was seen on chest X-ray and tuberculosis work up was negative. Child was started on oxygen, antibiotics, nebulisations and intravenous fluids. On day two of admission child developed rigorous bouts of cough associated with hypoxia, bradycardia, cyanosis and listlessness which improved on bag and mask ventilation. Following a strong suspicion of obstruction in the tracheobronchial tree, a Computed Tomography (CT) neck and chest was done which was suggestive of either an intratracheal or intrabronchial foreign body. Child was urgently taken up for rigid bronchoscopy and a ground nut was found in the right main bronchus. The FBA as a differential diagnosis of chronic cough in children should always be ruled out.
\end{abstract}

\section{Keywords: Cough, Groundnut, Paediatrics, Rigid bronchoscopy}

\section{CASE REPORT}

A 15-month-old, first order female child, born of non consanguineous marriage presented with complaints of intermittent low-grade fever, cough, cold for 20 days and increased breathlessness for one day. There was no history of refusal of feeds or post-tussive vomiting. The child was not fully immunised with the last dose been given at 14 weeks of age. Birth and development history were insignificant.

On examination, child had pallor, grade 3 protein energy malnutrition by weight for age criteria (Indian Academy of Paediatrics) with heart rate of $128 / \mathrm{min}$ and respiratory rate of $44 / \mathrm{min}$ [1]. The oxygen saturation was $88 \%$ on room air with nasal flaring, intercostal and subcostal retractions. Auscultation revealed bilateral rhonchi with reduced air entry in all the areas of the lung. The child was taken to numerous physicians, prescribed several antibiotics and cough suppressants since past three weeks with intermittent relief. The persistence of symptoms regardless of complete course of prescribed treatment was greatly distressing for the family. The child was referred to our centre in view of non resolution of symptoms.

On admission, investigations revealed a haemoglobin level of $10.4 \mathrm{gm} / \mathrm{dL}$ with a total leucocyte count of 19.1/cubic $\mathrm{mm}$ with neutrophils $83.7 \%$, platelets $8.8 \mathrm{lac} / \mathrm{\mu L}$ and $\mathrm{C}$-reactive protein was $26.8 \mathrm{mg} / \mathrm{L}$. Bilateral bronchopneumonia was seen on chest X-ray. Negative mantoux test, sputum for Gastric Lavage for Acid Fast Bacilli (GLAFB) and a normal Erythrocyte Sedimentation Rate (ESR) ruled out the possibility of tuberculosis.

The child was administered oxygen, antibiotics, nebulisations and supportive therapy. She had multiple episodes of cyanotic spells, following rigorous bouts of cough during hospitalisation. Each episode was associated with hypoxia, bradycardia, cyanosis and listlessness which responded to ventilation with artificial manual breathing unit and mask. A normal 2 Dimensional-Echocardiography ruled out the possibility of any cardiac abnormalities.

An X-ray and computed tomography of the neck [Table/Fig-1,2] and chest [Table/Fig-3] was performed suspecting a foreign body in view of recurrent cyanotic spells and deterioration in the clinical condition. The scan highlighted the presence of an intratracheal/ intrabronchial foreign body.
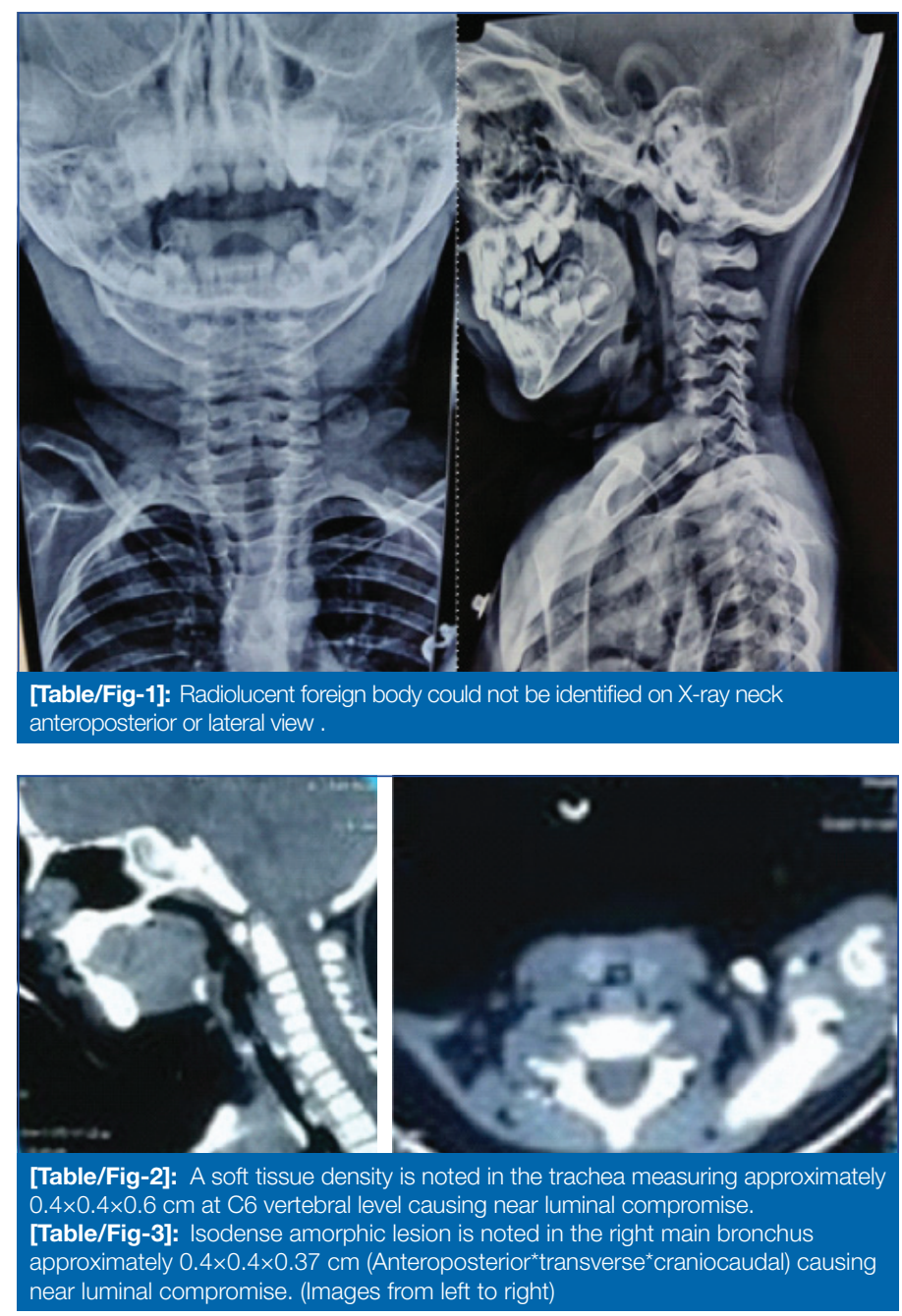
Rigid bronchoscopy was performed and a piece of groundnut was retrieved from the right main bronchus [Table/Fig-4,5]. The symptoms completely resolved postprocedure and patient was discharged on day eight of admission. The child on two weekly follow-up was asymptomatic and thriving well.
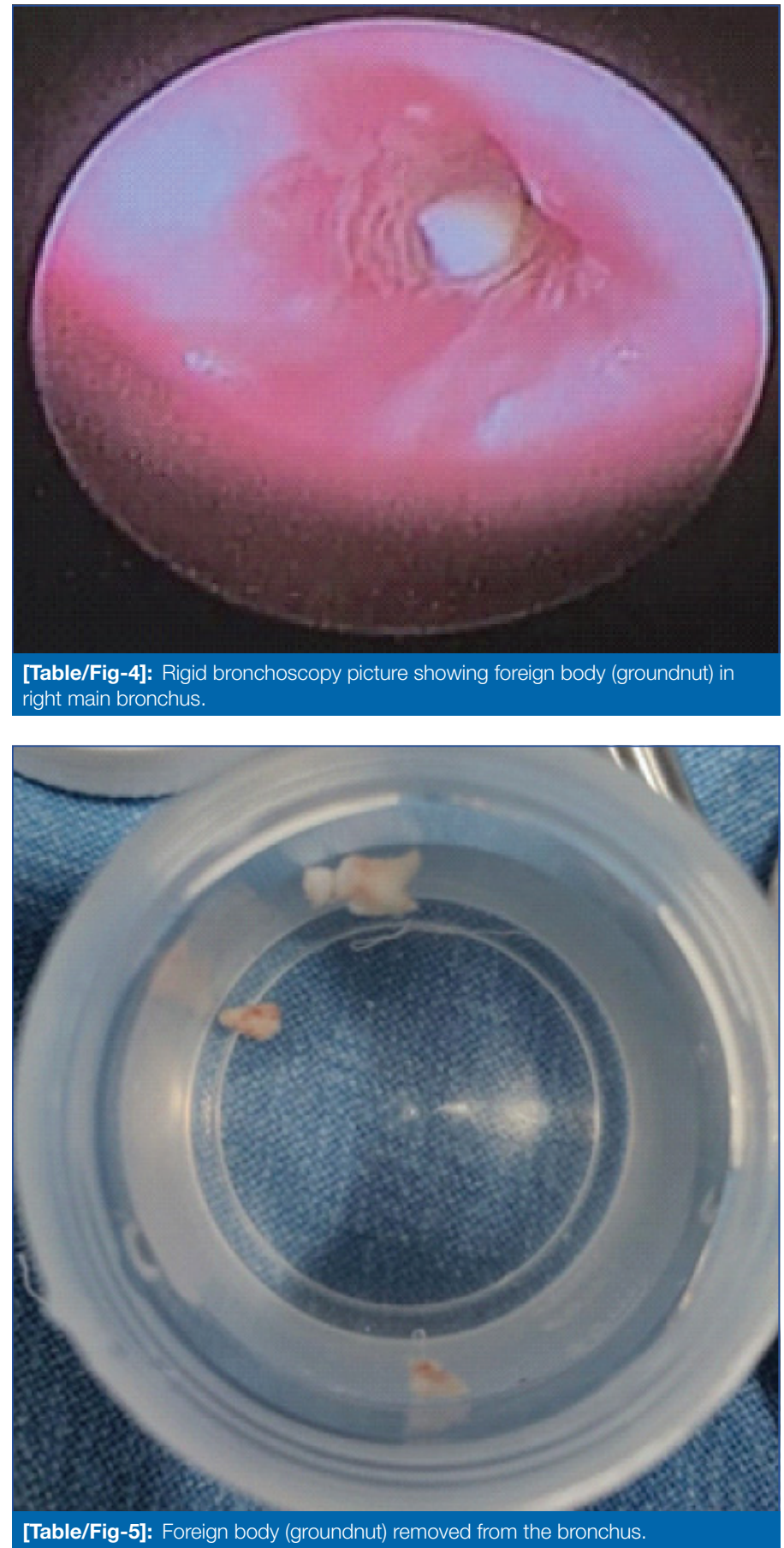

\section{DISCUSSION}

FBA is the foremost cause of sudden death in children $<5$ years with the mean age being 24 months [2,3]. It accounts for $7 \%$ of overall childhood mortality in the age group of 0-3 years and results in $40 \%$ accidental deaths in babies $<1$ year of age [2]. It is more commonly seen in boys (M/F: 1.2-2.6/1) as compared to girls [4]. Infants and toddlers are at a higher risk due to lack of adequate dentition, immature swallowing coordination and baby mouthing as a developmental milestone [5]. Increased curiosity to explore the surroundings, smaller airway diameter and weaker cough reflex further intensify vulnerability [6]. Coinciding with the presented data the index case was a 15-month-old female child.

Foreign bodies aspirated into the tracheobronchial tree are usually localised in the shorter, wider, acute angled right bronchus. However, in children, there is a predilection to either bronchus due to equal bronchial branching angles and sizes [7]. The foreign body in the index case, was lodged in the right main bronchus.

Sudden onset of acute cough followed by choking with or without wheeze, stridor or shortness of breath is observed amongst otherwise healthy children [8]. Choking associated with cyanosis as the predominant symptom is rare in children accounting for only $6 \%$ of total cases, however if present, they possess a sensitivity of $96 \%$ and a specificity of $76 \%$, respectively $[5,9]$. The classical triad of wheeze, paroxysmal cough and decreased air entry is usually seen in 35\% cases of FBA. The same study has highlighted the presence of any one symptom in $96 \%$ of the FBA cases [10].

Patients with sudden appearance of a wheeze without a previous history of asthma, especially if unilateral should raise suspicion about the lodgement of a foreign body in the respiratory tract [11]. A misdiagnosis of asthma, upper respiratory tract infection, pneumonia, or croup has been seen in literature due to lack of specific symptoms and radiological signs [12]. Index case presented with atypical manifestations of chronic persistent cough not responding to multiple cocktail of medications and being misdiagnosed as wheeze associated lower respiratory tract infection.

Nuts and seeds have been implicated in $70 \%$ to $90 \%$ of the cases [3]. Peanut is notoriously responsible but other organic foreign body, like groundnut, sunflower seed, etc., have also been found to cause symptoms [13]. These get swollen when lodged in the bronchus causing surrounding reaction, pooling of secretions and obstruction to air flow [3].

Anticipatory guidance of choking risks by primary healthcare workers including avoidance until the child is able to chew them adequately while sitting needs to be highlighted. Therefore, caregivers should be informed that children under the age of four should always be supervised while they eat nuts or other small, round, crunchy foods, making prevention the most effective treatment of foreign body injuries [14]. Immediate intervention using rigid bronchoscopy is essential, as delay in the diagnosis and treatment can lead to potentially lethal sequelae. Delayed diagnosis may lead to atelectasis, recurrent pneumonia, bronchial stenosis and lung abscess [15]. There is a record of a 10-month-old male infant with refractory pneumonia secondary to sunflower seed aspiration who developed pneumothorax and required a tracheostomy. Decannulation could only be performed after nine months [16].

The authors wish to raise awareness about the excessive use of over-the-counter cough suppressants being prescribed to children and their deleterious effects leading to delayed diagnosis. Thus, it is important to educate parents, family and the health care providers to help decrease the incidence of FBA and its complications.

\section{CONCLUSION(S)}

Healthy child presenting with chronic cough should raise a high index of suspicion of FBA requiring appropriate management. Creating awareness, sensitisation and counselling of parents or caregivers is crucial.

\section{REFERENCES}

[1] Khadilkar W, Khadilkar AV, Choudhury P, Agarwal KN, Ugra D, Shah NK. IAP growth monitoring guidelines for children from birth to 18 years. Indian Pediatr. 2007;44:187-97.

[2] Skoulakis CE, Doxas PG, Papadakis CE, Proimos E, Christodoulou P, Bizakis JG et al. Bronchoscopy for foreign body removal in children. A review and analysis of 210 cases. Int J Podiatry Otorhinolaryngol. 2000;53:143-48

[3] Even L, Lea E, Heno N, Nawaf H, Talmon Y, Yoav T, et al. Diagnostic evaluation of foreign body aspiration in children: A prospective study. J Pediatr Surg. 2005;40(7):1122-27

[4] Sinha V, Chhaya V, Barot DS, Mehta K, Patel P, Patil S, et al. Foreign body in tracheobronchial tree. Indian J Otolaryngol Head Neck Surg. 2010;62:168-70.

[5] Oğuz F, Citak A, Unüvar E, Sidal M. Airway foreign bodies in childhood. Int J Pediatr Otorhinolaryngol. 2000;52:11-16.

[6] American Academy of Pediatrics. Policy statement- prevention of choking among children. Pediatrics. 2010;125:601-07. 
[7] Bittencourt PF, Camargos PA, Scheinmann P, de Blic J. Foreign body aspiration: Clinical, radiological findings and factors associated with its late removal. Int $\mathrm{J}$ Pediatr Otorhinolaryngol. 2006;70:879-84.

[8] Bressler KL, Green CG, Holinger LD. Chapter 27-Foreign Body Aspiration. In: Taussig LM, Landau LI (eds). Pediatric Respiratory Medicine. 1999, Carlsbad: St. Louis: Mosby, Pp. 430-35.

[9] Passali D, Lauriello M, Bellussi L, Passali GC, Passali FM, Gregori D. Foreign body inhalation in children: An update. https://www.ncbi.nlm.nih.gov/pmc/articles/ PMC2881610/ACTA Otorhinolaryngol Ital. 2010;30:27-32.

[10] Hilliard T, Sim R, Saunders M, Hewer SL, Henderson J. Delayed diagnosis of foreign body aspiration in children. Emergency Medicine Journal. 2003;20:100-01.

[11] Sehgal A, Singh V, Chandra J, Mathur NN. Foreign Body Aspiration. Indian Pediatrics. 2002;39:1006-10.

[12] Liu B, Ding F, An Y, Li Y, Pan Z, Wang G, et al. Occult foreign body aspirations in pediatric patients: 20-years of experience. BMC Pulm Med. 2020;20:320.
[13] Asif M, Shah SA, Khan F, Ghani R. Analysis of tracheobronchial foreign bodies with respect to sex, age, type and presentation. J Ayub Med Coll Abbottabad. 2007:19:13-15.

[14] Gregori D, Salerni L, Morra B, Scarinzi C, Berchialla P, Snidero S, et al. Foreign bodies in the upper airways causing complications and requiring hospitalization in children aged 0-14 years: Results from the ESFBI study. Eur Arch Otorhinolaryngol. 2008;265:971-78.

[15] Dorterler ME, Kocaman OH, Gunendi T, Boleken ME. A single-center experience of pediatric foreign-body aspiration: A retrospective 4-year case series. Lung India. 2019;36:202-06.

[16] Aslan N, Yıldızdaș D, Özden Ö, Yöntem A, Horoz ÖÖ, Kılıç S. Evaluation of foreign body aspiration cases in our pediatric intensive care unit: Single-center experience. Turk Pediatri Ars. 2019;54(1):44-48.

\section{PARTICULARS OF CONTRIBUTORS:}

1. Resident, Department of Paediatrics, DY Patil School of Medicine, Navi Mumbai, Maharashtra, India.

2. Associate Professor, Department of Paediatrics, DY Patil School of Medicine, Navi Mumbai, Maharashtra, India

3. Professor, Department of Paediatrics, DY Patil School of Medicine, Navi Mumbai, Maharashtra, India.

4. Senior Resident, Department of Paediatrics, DY Patil School of Medicine, Navi Mumbai, Maharashtra, India.

5. Resident, Department of Paediatrics, DY Patil School of Medicine, Navi Mumbai, Maharashtra, India.

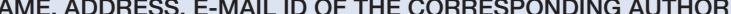

Pallavi Wadhawan,

Resident, Department of Paediatrics, DY Patil School of Medicine,

Navi Mumbai, Maharashtra, India.

E-mail: pallavi.wadhawan@gmail.com

\section{AUTHOR DECLARATION:}

- Financial or Other Competing Interests: None

- Was informed consent obtained from the subjects involved in the study? Yes (From parents)

- For any images presented appropriate consent has been obtained from the subjects. Yes (From parents)
PLAGIARISM CHECKING METHODS: [Jain $\mathrm{H}$ et al.]

- Plagiarism X-checker: Apr 03, 2021

- Manual Googling: Jun 28, 2021

- iThenticate Software: Jul 30, 2021 (11\%)
ETYMOLOGY: Author Origin

Date of Peer Review: May 29, 2021

Date of Acceptance: Jul 21, 2021 Date of Publishing: Oct 01, 2021 